\title{
Spontaneous Closure of Pediatric Traumatic Macular Hole
}

Karmoun S*, Elmarzouqi B, Tamym B, Elhassan A, Aboulanouar A, Berraho A

Service d'ophtalmologie B, Hôpital des spécialités de Rabat, Morocco

DOI: $10.36347 /$ sjams.2020.v08i06.028

| Received: 17.06.2020 | Accepted: 24.06.2020 | Published: 26.06.2020

*Corresponding author: Karmoun Souhaila

\section{Abstract}

\section{Case Report}

Macular hole formation is a well-known complication following ocular trauma. Less commonly recognized is the spontaneous closure of such holes. Optical coherence tomography (OCT) and clinical follow-up enabled monitoring of this resolution during a period of a few weeks. We describe a case of spontaneous closure of a Traumatic macular hole (TMH) with complete visual recovery of a 12-year-old boy, and we will show the follow-up of the macular hole obtained using the OCT. Observation for a period of up to 12 months is a reasonable management option. Macular hole surgery for traumatic macular holes may be delayed in such cases.

Keywords: Optical coherence tomography (OCT), macular hole, surgery.

Copyright @ 2020: This is an open-access article distributed under the terms of the Creative Commons Attribution license which permits unrestricted use, distribution, and reproduction in any medium for non-commercial use (NonCommercial, or CC-BY-NC) provided the original author and source are credited.

\section{INTRODUCTION}

Traumatic macular hole (TMH) is a wellknown complication of blunt trauma, but its exact mechanism remains unclear. Spontaneous closure of a $\mathrm{TMH}$ is reported to occur in $10-66 \%$ of cases in adults $[1,2]$. Spontaneous closure has been reported to occur for small traumatic macular holes in young patients [24].

There is no study comparing the surgical approach versus expectant management in pediatric traumatic macular hole. We report spontaneous closure of a large macular hole with complete visual recovery in a young boy following trauma and postulate the possible mechanisms underlying it.

\section{CASE RePORT}

A 12-year-old boy presented with a large macular hole 25 days after a blunt trauma to his right eye. He first noted blurred vision 10 days after the injury. His best-corrected visual acuity of the affected eye was $1 / 10$. The intraocular pressure was $11 \mathrm{mmHg}$. The anterior Biomicroscopy was normal with no signs of intraocular inflammation or phacodonesis. Fundus examination revealed an oval, full-thickness macular hole (Figure-1), but no retinal detachment was observed. The Watzke-Allen test was positive. The left eye was normal.

Fundus fluorescein angiography showed a hyperfluorescent window defect corresponding to the macular hole (Figure $2 \& 3$ ).
The OCT of the left eye, performed (Figure-4), shows a full thickness macular hole and a scar of fibrosis in pigment epithelium.

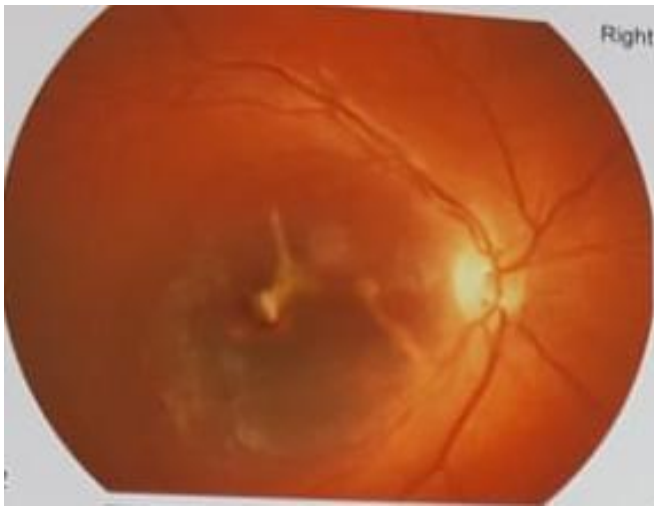

Fig-1: Colour fundus photograph of the right eye shows a full thickness macular hole

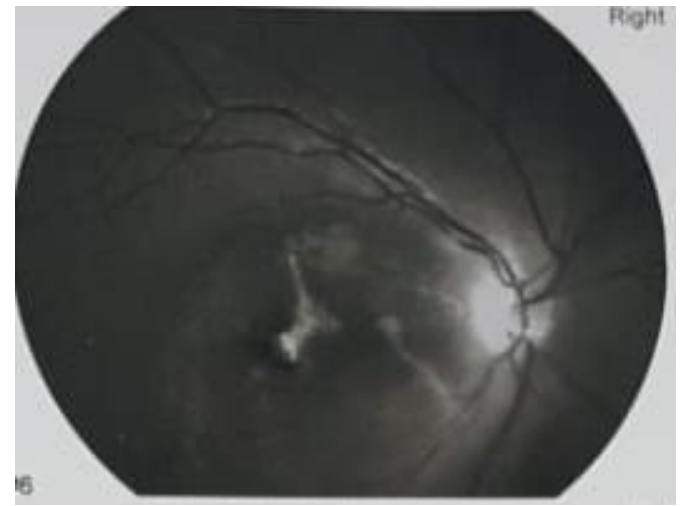

Fig-2: Fluorescein angiography showed a hyperfluorescent window defect corresponding to the macular hole 


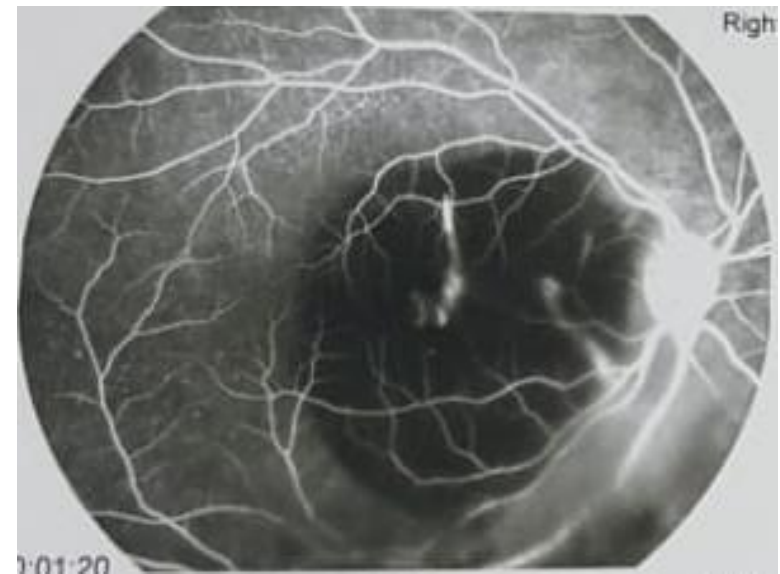

Fig-3: Fluorescein angiography showed a hyperfluorescent window defect corresponding to the macular hole

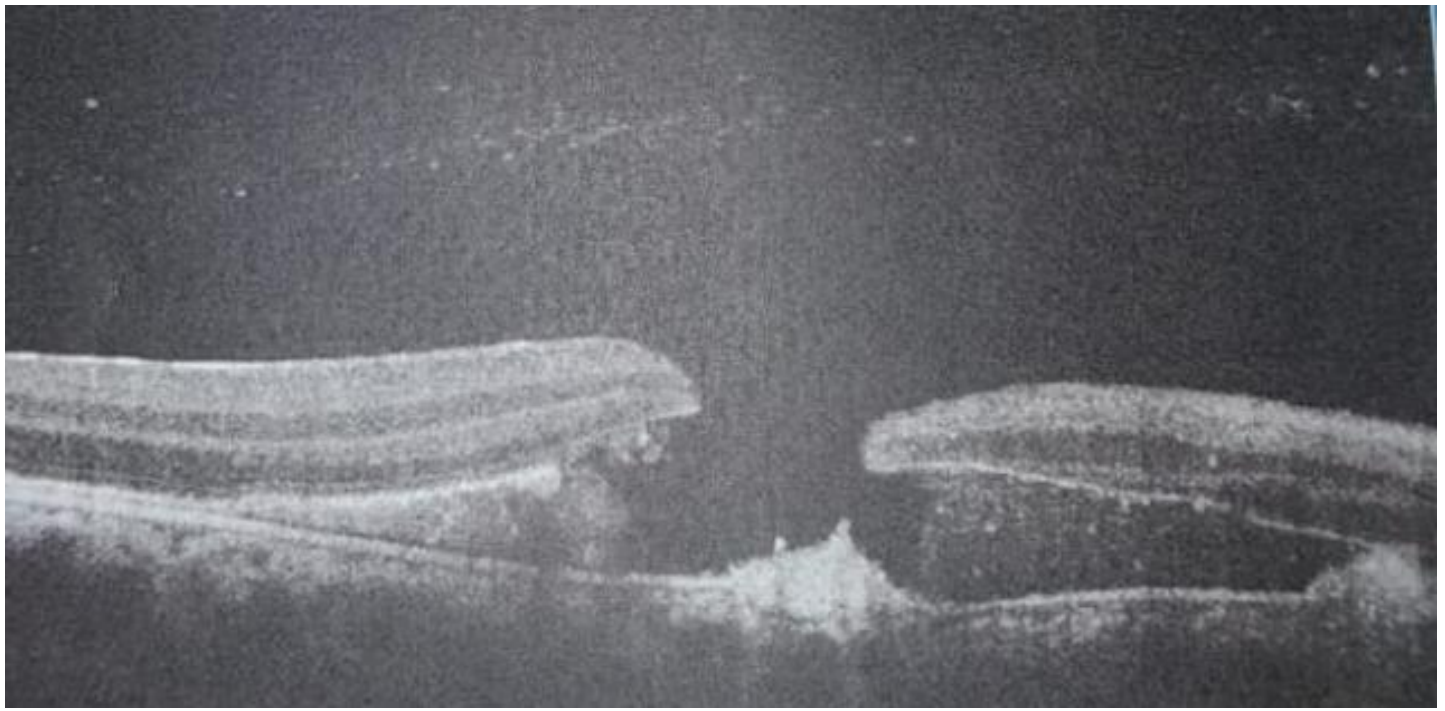

Fig-4: Shows a full thickness macular hole and a scar of fibrosis in pigment epithelium

Eight weeks after the first exam, the bestcorrected visual acuity improved from 1/10 to 7/10. Complete resolution of the macular hole was observed, as determined by both fundoscopy and OCT imaging (Figure $5 \& 6$ ). At this time, the OCT showed a complete resolution of the full-thickness macular hole. Macular hole surgery was not performed at this time due to the guarded prognosis from extensive subretinal fibrosis.

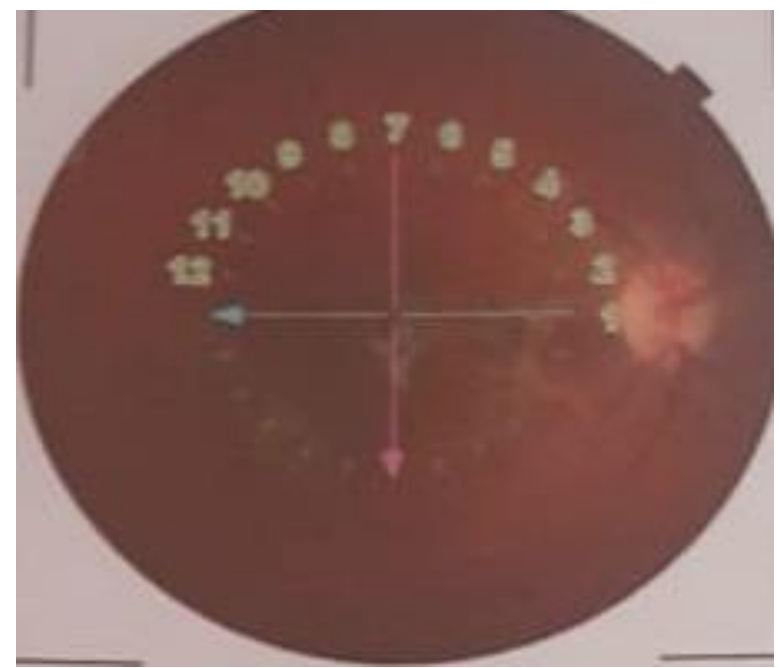

Fig-5: Resolution of the macular hole in fundoscopy 

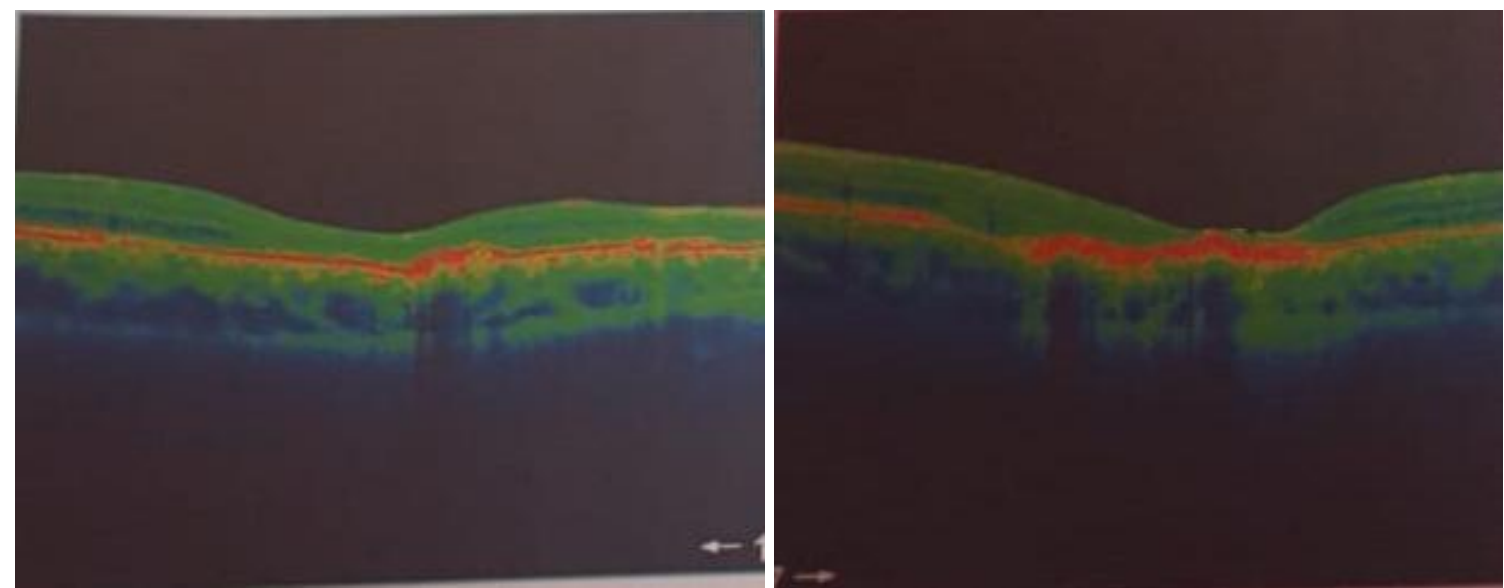

Fig-6: Resolution of the macular hole in OCT

\section{DISCUSION}

Blunt ocular trauma is associated with a number of retinal complications, including Berlin's edema, peripheral retinal tears and dialysis, vitreous hemorrhage, choroidal rupture, subretinal hemorrhage, and macular holes.

Eyeball trauma is one of the main causes of $\mathrm{TMH}$, and was first reported by Knapp in 1869. Two different mechanisms are believed to lead to the formation of $\mathrm{TMH}$, depending on whether the posterior hyaloid is attached or detached. In the setting of blunt trauma, the most common cause of macular hole in children, a contrecoup mechanism as a result of axial globe compression is thought to increase vitreomacular traction forces [6].

In the case in question, the OCT showed a TMH with an intact posterior vitreous face already 25 days after the injury. These findings suggest that the TMH was produced as a concussive tear. In other reports, several explanations have been proposed for the spontaneous resolution of TMH: cell proliferation at the base of the hole; formation of a contractile epiretinal membrane resulting in shrinkage and closure of the hole, and complete detachment of the posterior hyaloid from the foveal area resulting in the release of an antero-posterior traction [7]. The first explanation is of significance regarding the case under review. The small opening of the TMH could have favored the proliferation of glial cells to bridge the gap. The development of an epiretinal membrane was not observed. The third explanation was not applicable to the patient because there was no evidence of vitreoretinal traction, and the vitreous body remained attached throughout the follow-up period. The relatively higher rate of spontaneous closure of TMH (10-66\% in adults) $[1,2]$ may be explained by an adherent posterior vitreous membrane [8].

There are only a few case series, which studied the natural history of traumatic macular hole. In 2002, Yamashita et al., reported 8 out of $18(44.4 \%)$ traumatic macular holes that closed spontaneously after a mean follow-up of 8.4 months [2]. Li et al., reported 3 out of $28(10.7 \%)$ traumatic macular holes which closed spontaneously after a mean follow-up of 18 months [9]. Faghihi reported 6 cases with spontaneous closure of traumatic macular hole after 1- to 6-month follow-up [3].

Since significant proportion of traumatic macular hole close spontaneously with improvement in vision, it has been recommended that traumatic macular hole should be followed up and observed for at least several months before surgery to avoid unnecessary risk of surgical complications [2].

We found that OCT imaging is useful in visualizing anatomical $\mathrm{TMH}$ closure. In our case, anatomical TMH closure correlated with visual recovery.

Further studies will be necessary to determine the exact association between macular hole closure and ultimate visual recovery.

\section{Conclusion}

Significant visual recovery is possible even in the presence of associated chorioretinal atrophy. Serial OCT imaging of the macular hole is useful in gauging ultimate visual recovery.

More data will be necessary to determine whether the surgical or expectant approach is the most appropriate for traumatic macular holes in children.

\section{REFERENCES}

1. Mitamura Y, Saito W, Ishida M, Yamamoto S, Takeuchi S. Spontaneous closure of traumatic macular hole. Retina. 2001;21(4):385-9.

2. Yamashita T, Uemara A, Uchino E, Doi N, Ohba N. Spontaneous closure of traumatic macular hole. Am J Ophthalmol. 2002;133(2):230-5.

3. Faghihi H, Ghassemi F, Falavarjani KG, Saeedi Anari G, Safizadeh M, Shahraki K. Spontaneous 
closure of traumatic macular holes. Can J Ophthalmol, 2014;49:395-8

4. Chen H, Chen W, Zheng K, Peng K, Xia H, Zhu L. Prediction of spontaneous closure of traumatic macular hole with spectral domain optical coherence tomography. Sci Rep, 2015;5:12343

5. Kelly NE, Wendel RT. Vitreous surgery for idiopathic macular holes. Results of a pilot study. Arch Ophthalmol, 1991;109:654-9.

6. Johnson RN, McDonald HR, Lewis H, Grand MG, Murray TG, Mieler WF, Johnson MW, Boldt HC, Olsen KR, Tornambe PE, Folk JC. Traumatic macular hole: observations, pathogenesis, and results of vitrectomy surgery. Ophthalmology. 2001 May 1;108(5):853-7.
7. Takahashi H, Kishi S. Optical coherence tomography images of a spontaneous macular hole closure. Am J Ophthalmol. 1999;128(4):519-20.

8. Yanagiya N, Akiba J, Takahashi M, Shimizu A, Kakehashi A, Kado M, Hikichi T, Yoshida A. Clinical characteristics of traumatic macular holes. Japanese journal of ophthalmology. 1996;40(4):544-7.

9. Li XW, Lu N, Zhang L, Wang WW, Wang Y, Yan W, Xiong Y. Follow-up study of traumatic macular hole. [Zhonghua yan ke za Zhi] Chinese Journal of Ophthalmology. 2008 Sep 1;44(9):7869. 